\title{
La bella durmiente: análisis de algunas versiones tradicionales y sus reescrituras
}

The sleeping beauty it's a research and analysis of some traditional versions and rewritings

\author{
Natalia Ramírez S. ${ }^{1}$ \\ Universidad Autónoma de Madrid, España. \\ Universidad Nacional Mayor de San Marcos, Lima, Perú. \\ (RECIBIDO 08-08 2014, ACEPTADO 20-11-2014)
}

\begin{abstract}
RESUMEN
El ensayo tiene como objetivo cristalizar los estereotipos y limitaciones que se vienen imponiendo a la mujer en la literatura infantil. Se analiza uno de los cuentos de hadas de mayor predilección entre la población infantil: La Bella durmiente. Se revisarán sus versiones tradicionales y se examinará su contenido mediante tres enfoques: psicoanalítico, jungiano y feminista. Posteriormente se presentan algunas versiones reescritas en la actualidad y se finaliza con las conclusiones a las que se llegan tras el análisis.
\end{abstract}

Palabras clave: Cuento de hadas, arquetipo, imaginario colectivo, inconsciente, proceso identificatorio, estereotipo y género.

\begin{abstract}
It' $s$ an essay that tries to crystallise the límits and the stereotypes that we have read about women in fairy tales in Children literature. We have analysed the most famous and well known fairy tale that everybody loves The Sleeping Beauty. We are going to revise the traditional versions and analyse the same content by three approaches: The Feminist, The Jungian and The Psychoanalytic. Finally, nowadays we have shown rewriting versions and after the analysis we have just arrived to the conclusions.
\end{abstract}

Keywords: Fairy tale, archetype, collective imagination, unconscious, identifying process, stereotype and gender. 


\section{INTRODUCCIÓN}

El presente ensayo tiene como objetivo cristalizar los estereotipos y limitaciones que se vienen imponiendo a la mujer en la literatura infantil, lenguaje al que nos acercamos desde nuestros primeros años de vida y en donde se transmite la estructura patriarcal, aún con fuerte dominio en nuestra sociedad.

Los cuentos de hadas son únicos en su forma literaria, su significado es diferente para cada lector e inclusive puede diferir cuando se relee el texto en diferentes momentos de la vida.

La diversidad de historias y sus reescrituras fueron condensándose, fundiéndose o ampliándose a lo largo del tiempo. Todas han sido modificadas según lo que el narrador pensaba era de interés para los oyentes, según sus propias inquietudes y segun los problemas concretos de su época.

Es el cuento de la bella durmiente que despierta un especial interés en la población infantil con la que trabajo, que motivada por escucharla la solicitan en sus espacios familiares y en las sesiones terapéuticas llevadas a cabo con quien suscribe el presente ensayo.

Considero de responsabilidad ética y profesional, indagar desde diversas perspectivas el análisis, tanto del cuento en sus versiones tradicionales, como de las versiones reescritas y pertenecientes a nuestra época.

\section{Generalidades a considerar en los cuentos de hadas}

Son los mitos, las fábulas y las parábolas aquello que nutre a las diversas manifestaciones artísticas y culturales como la pintura, la literatura o el cine, entre otros. Está integrado por componentes arquetípicos de representaciones sociales y se reutilizan en diversas composiciones, que traducen fantasías pertenecientes a imágenes y símbolos del imaginario colectivo de la sociedad en la que se producen.

(...) cada texto responde a un sistema de convenciones sociales y estéticas determinado, propio del momento histórico en que se crea, que explica tanto las características del mensaje como las razones por las que fue creado o la función que implícita o explícitamente se le atribuye (Sotomayor, 2005, p. 218).

Según De La Concha (2010), los cuentos de hadas son una práctica cultural que ha configurado una organización social en virtud del género, es decir, asignando roles determinados a hombres y mujeres en función de sus atributos sexuales. Como todo proceso social, el resultado es una estructura producto de una dinámica de fuerzas y resistencias, que suelen ser recubiertas por los cambios culturales que se refuerzan mutuamente. Plantea que los diversos problemas de género tienen sus orígenes en la organización social, los que se ven traducidos en los cuentos y, en muchas ocasiones, las coincidencias con la realidad vivida se hacen evidentes, al respecto señala: "La inmersión en esos espacios imaginarios requiere ese estado de voluntaria suspensión de la incredulidad -en la perceptiva acuñación del crítico romántico Coleridge- que nos predispone a absorber, a menudo indiscriminadamente, los discursos subyacentes" (Sotomayor, 2005, p.8). 
Los problemas de género, como la violencia, han adoptado múltiples formas a lo largo de la historia,con unas más visibles que otras, aunque las menos visibles han sido las más insidiosas, por actuar bajo sutiles máscaras que la han ocultado, haciéndola más aceptable por estar inmersa en contenidos científicos, morales, psicológicos o artísticos, y que, al mismo tiempo, están activamente operantes en la cultura.

Como afirma Salmueron (2004), en la actualidad existe una mayor conciencia social sobre la importancia e influencia que tienen los cuentos en el desarrollo del niño, en especial en lo que concierne al aspecto afectivo, emocional y social.Expresa que "...el cuento es considerado como un instrumento transmisor de cultura y por lo mismo de valores" (p. 86).

La investigación aludida concluye que los valores que se transmiten a través de los cuentos no aparecen como algo independiente, sino que se relacionan estrechamente con la voz del narrador y la de los personajes, que están enmarcados dentro del plano ético, afectivo y corporal; y que las reescrituras materializan las reivindicaciones de las diferentes corrientes, en sintonía con los valores emergentes de la sociedad actual.

\section{Algunas versiones tradicionales del cuento de La bella durmiente}

1. Cuento indio Surya Bai

Fernández (1998) ubica el lugar de origen del cuento de la bella durmiente en la India, luego fue recogido de la tradición oral y publicado por Mary Frere, en 1868. Refiere, las críticas de G. Franci y E. Zago para otorgar fuentes de dicha gesta, las mismas que ofrecen una versión popular en donde la protagonista, Surya Bai, es raptada y criada por unas águilas, quien luego de clavarse una uña envenenada del hijo de una vieja bruja que desea comérsela, cae muerta. Al poco tiempo un rajá, que se presenta en escena, le extrae la uña y ella despierta. El héroe la lleva a su mansión, empezando la segunda parte de la historia, en donde la primera esposa del rajá, la asesina por rivalidad femenina y ella se transforma primero en girasol, luego en mango y finalmente regresa a su forma humana. En este recorrido, el rajá vuelve a descubrirla, la reconduce al palacio, reconociéndola como la única y verdadera esposa, y a la primera consorte la castiga con la cárcel.

2. Versiones medievales europeas

Fernández (1998) cita a Franci y Zago para expresar que en las versiones medievales europeas existe una estrecha ligazón con la versión india, pero no tratan el tema de la rivalidad femenina y se mantienen en aquello que motiva el despertar de la heroína; es decir, la intervención masculina. Destacan dos versiones:

- Hermano de alegría, hermana de placer

Novela catalana que constituye una de las versiones literarias más antiguas de la bella durmiente, data del siglo XIV, pero es publicada por primera vez por Paul Meyer en 1884, y es considerada por Zago como el primer ejemplo en la literatura 
europea que trata el tema del mencionado cuento que concita nuestro interés.

Relata la historia como Hermana de placer muere durante un festín sin causa aparente, su padre la traslada a una torre fuera de la ciudad, la que se rodea de jardines y un río. Un príncipe, de nombre Hermano de Alegría, sabiendo lo ocurrido, logra entrar en la torre y convierte inicialmente a la heroína en esposa y madre, para luego pasar a resucitarla depositando unas hierbas en su mano.

- $\quad$ Perceforest

Data también del siglo XIV, en donde tres diosas asisten a la ceremonia en honor de Zellandine, una de ellas lanza una maldición que es atenuada por otra. Cumplida la maldición, el padre deposita el cuerpo dormido y desnudo de su hija en una torre, que tras ser descubierto por Troylus, la viola y engendra engendrando un hijo, que en su momento succiona el dedo de la heroína y se convierte en su liberador.

3. Versiones clásicas

Son tres las versiones más difundidas.

- Basile

Fernández (1998) expresa que fue escrita en 1634 por G. Basile y titulada "Sol, Luna y Talía”. El argumento se divide en dos partes, en la primera se narra que los adivinos auguraron que la heroína correría un gran peligro, causado por una arista de lino. El padre intentó evitar el infortunio, pero la profecía se cumplió y Talía cae muerta, el padre la abandona, y la deja sola en el palacio. Otro rey, que entra al palacio buscando su halcón, se queda deslumbrado por la belleza de la princesa y la viola, producto de ello nacen dos niños, que son cuidados por hadas, hasta que uno de ellos le chupa el dedo y le extrae la arista, despertándola. En la segunda parte, el rey que la descubrió retorna y le explica lo ocurrido, pero la reina, esposa de este, enterada del suceso encarga que los maten y se los den de comer al monarca, pero el cocinero, desobedeciendo la orden, los oculta, y el rey que luego lo recompensará, al enterarse de sus intenciones ordena matar a su esposa y se casa con la heroína, con quien disfruta de una larga vida.

- $\quad$ Perrault

Siguiendo el mismo texto, se señala que esta versión fue publicada por primera vez en 1696 y su argumento también consta de dos partes. En la primera, se acuñan motivos de las desdichas de la princesa y el relato presenta a unos padres con una esterilidad prolongada. Cuando logran concebir, realizan una fiesta en honor al bautizo de la niña, en envitan a siete hadas buenas, pero una octava se presenta. Al sentirse excluida, lanza una maldición de muerte que es atenuada por una que faltaba otorgar el don, señalando que caería en un profundo sueño. La maldición se cumple al llegar a los 15 años, siendo dormidos también todos los que habitaban el castillo, a excepción de los reyes, que abandonan el palacio, el que es rodeado de espinos. Transcurridos 100 años, un príncipe, informado de lo sucedido, se enfrenta a los obstáculos hasta que logra llegar donde yace la princesa, quien lo 
deslumbra con su belleza; él se arrodilla y ella despierta, ambos se enamoran y se casan posteriormente. En la segunda parte, se narra que el príncipe pasaba algunos días viviendo con sus padres, quienes desconocían su matrimonio, hasta que el padre muere y se permite trasladar a la princesa y sus dos hijos a palacio, pero cuando el ahora rey tuvo que salir a enfrentar una guerra, la reina madre exige al mayordomo la muerte de los tres llegados, pero este los esconde hasta el retorno del héroe, quien libera a su esposa e hijos y la reina madre se suicida.

- Hermanos Grimm

También conocida por el título de Rosa silvestre, aparece por primera vez en 1812. Su argumento es lineal y presenta el tema de la infertilidad de los reyes. Un sapo anuncia a la reina será madre, nace la niña y se celebra su llegada al reino con una fiesta, a la que se invita a doce hadas que otorgan atributos considerados femeninos, pero una adicional se presenta al festejo, quien, ofendida por la exclusión, la maldice con la muerte, pero una que faltaba otorgar el don cambia la sentencia; solo sería un profundo sueño. Pese a las precauciones tomadas por el rey, en el cumpleaños 15, la maldición se cumple y todos, incluyendo a sus padres y demás habitantes del palacio, caen en un sueño profundo. El palacio es cubierto de espinos, muchos libertadores fracasaron en el intento por deshacer el hechizo, hasta que transcurridos 100 años, un príncipe logra llegar y besa a la princesa, logrando con ello que todos despierten en el palacio y posteriormente se realiza el matrimonio, con un final, de felicidad eterna.

\section{Análisis de los estereotipos y del argumento}

- Estereotipos

Personajes masculinos: Entre ellos tenemos al rey, el príncipe, el cocinero o el mayordomo; tienen el papel de libertadores, en algunas versiones disfrutan de una libertad sexual absoluta y aparecen indicadores de trasgresiones sexuales como la necrofilia, así como, de violencia sexual, esta última es la que “...constituye, a juicio de N. Aisenberg, uno de los rasgos característicos de los cuentos de hadas" (Fernández,1998, p. 35).

Bados (2007) menciona a Bettelheim para indicar que el objetivo del héroe masculino es el poder y que la mujer es su jurisdicción, la que, refiere, tendrá como aspiración casarse para ser rescatada de sus problemas y ser protegida. La autora afirma que esos discursos proporcionaban maneras de conducta que satisfacían a las altas clases europeas del siglo XVII, que buscaban establecer el orden patriarcal; de este modo, la construcción de género se fue transmitiendo a través de los cuentos de hadas.

Personajes femeninos: Son de dos tipos buenas y malas, en función del poder; las del primer grupo son adornadas, caracterizadas por la bondad, la virginidad, la capacidad para ser madre, la belleza y la pasividad. Las del segundo rivalizan, son maquiavélicas, agresivas, y finalmente son abandonadas o se suicidan, porque otra mujer cumple los ideales patriarcales de la femineidad. 
Para Correa y Perera (2007), el héroe suele ser osado y valeroso, que se arriesga para reparar una injusticia y el personaje femenino constituye el premio, el objeto final de su valor, en ella destaca características como la belleza, la bondad y la resignación; y no dignifica su carácter.

- Argumento

Mediante encumbramientos de la femineidad, como máximo valor en la mujer, la reducen a ser figura simbólica, con una función social estrechamente delimitada. Las razones confluyen en estar al servicio de la mantención de la estructura de la sociedad patriarcal. A este respecto tenemos: “...proponiendo identidades modélicas que responden al discurso patriarcal sobre la femineidad y recompensando a las heroínas con premios trampa, el más popular, el del matrimonio con el héroe atractivo que le prometía el reinado de su corazón..." (De La Concha, 2010, p. 9).

\section{Enfoques teóricos para el estudio del cuento de La bella durmiente}

- Psicoanalítico

Bettelheim (1990) afirma que en la literatura infantil lo que enriquece y satisface son los cuentos de hadas, ya que se puede aprender de los problemas internos de los seres humanos y de las soluciones a sus dificultades en cualquier sociedad.

A través del tiempo, los cuentos han llegado a transmitir sentidos evidentes y ocultos, llegando a dirigirse simultáneamente a todos los niveles de la personalidad, aportando mensajes al consciente, preconsciente e inconsciente.

Señala como conflicto existencial la necesidad de dominar los problemas psicológicos del crecimiento, para ello el niño necesita comprender lo que le está sucediendo y enfrentarse a sus temores inconscientes. Es aquí que los cuentos de hadas tienen un gran valor aportando a su imaginación nuevas dimensiones; y, expresa, que es inevitable luchar contra las adversidades.

El autor revela existen dos partes en las historias: el bien y el mal, condensados en sus personajes, los cuales son polarizados en la psique del menor. Sitúa su análisis en el final feliz como aleccionador, como experiencia en la educación moral, provocando un proceso identificatorio con los personajes; así, el héroe encuentra su recompensa y el personaje malvado el castigo, satisfaciendo el sentido de la justicia en el niño.

La vida intelectual y social de un niño ha dependido de historias míticas y de los cuentos de hadas, porque alimentan su imaginación y estimulan su fantasía.

Sostiene que el cuento es terapéutico, porque el paciente encuentra sus propias soluciones, mediante la contemplación de lo que la historia parece aludir sobre sí mismo y sobre sus conflictos internos. Los cuentos de hadas representan una integración del yo que permite una satisfacción adecuada de los deseos del ello. 
Cita a Piaget para afirmar que el pensamiento del niño sigue siendo animista hasta la pubertad. Las explicaciones realistas son a menudo incompresibles para los niños, ya que no poseen aún el pensamiento abstracto para captar su sentido. Solo pueden obtener seguridad si tienen la convicción de que comprende ahora lo que antes era incomprensible, pero nunca a partir de hechos que les aporten nuevas incertidumbres.

El autor sitúa el cuento de la bella durmiente en la adolescencia, describiéndolo como un período de grandes y rápidas transformaciones, alternándose etapas de gran pasividad y letargo e incluso de comportamientos arriesgados para probarse o descargar la tensión interna. Asimismo, menciona el conflicto de la primera menstruación no solo para la púber, sino para el contexto familiar. Las chicas dan muestras de cierta pasividad; dormidas y sumidas en sí mismas, justifica dicha necesidad con el objetivo de lograr un desarrollo satisfactorio.

Menciona que se encuentran más difundidas dos versiones, la de Perrault y la de los hermanos Grimm, aunque hace una breve descripción de la de Basile, Sol, Luna y Talía, esta última nos permite visualizar un conflicto edípico, cuando relata cómo un rey sustituye a otro en un mismo país. La de Perrault añade la maldición del hada despreciable, lo que enriquece la historia porque explica porque la heroína cae en ese profundo sopor; tiene dos partes: la primera cuando el príncipe despierta a la bella durmiente y se casa con ella; y la segunda, en la que la madre del príncipe es una mujer-ogro que intenta comerse a sus nietos. La de los hermanos Grimm termina en la feliz unión de los personajes.

Me parece destacable los símbolos tratados bajo el saber psicoanalítico, entre ellos tenemos: número de hadas (13 en los hermanos Grimm, 12 buenas y una malvada, relacionándolo con el tema de la menstruación, ya que coincide con los 13 meses lunares en los que antiguamente se dividía el año y con que el ciclo menstrual aparece cada 28 días, según la frecuencia de dichos meses), los dones, la maldición (que representa de modo latente una bendición), la edad de la joven al pincharse (15 en los hermanos Grimm, tiempo en que solía aparecer la menstruación), su exploración por las áreas del palacio antes inaccesibles, aludiendo a la escalera de caracol (experiencias sexuales), habitación cerrada (órganos sexuales femeninos) y las llave de la cerradura (relación sexual); la rueca (hilar y tejer eran ocupaciones femeninas), el encuentro con la mujer anciana (de acuerdo a la Biblia la menstruación se heredaba de mujer a mujer), el hada buena y el cambio al sueño profundo, el muro de espinos convertido en seto de flores (cambio de los obstáculos transcurrido el tiempo necesario para la ansiada madurez), el letargo (belleza fría de la heroína, considerado un símil del aislamiento propio del narcisismo), el beso del príncipe (es mutuo el despertar, símbolo que comporta madurez y no solo armonía dentro de uno mismo, sino también con el otro).

El autor concluye con el final feliz señalándolo como un objetivo de la vida y comentando que todas estas experiencias son femeninas e ilustran etapas por las que las mujeres deben pasar antes de alcanzar la valorada femineidad. 
Estas afirmaciones constituyen espacios para la crítica a este enfoque por su reduccionismo y contribución a estereotipos de la sociedad patriarcal.

- Jungiano

Considerado por Fernández (1998) como un enfoque de narración positiva, de reflejo del inconsciente colectivo, con funciones terapéuticas, e identifica como sus representantes a Von Franz 1993, Nelson 1991 y Heuscher 1963.

Esta perspectiva relaciona el análisis de los cuentos a la construcción del ego masculino y femenino, de manera independiente a las cuestiones de género. El final de unión mediante el matrimonio de los príncipes es el símbolo de la necesaria unión de dos contrarios para conseguir un ego desarrollado y maduro, planteamiento también criticado por similares razones a las del anterior enfoque.

- Feminista

Este enfoque revela la implicancia de problemas que están relacionados con la asignación sexista de los personajes del cuento.

“...El relato de la bella durmiente es perjudicial por el modo en que propone una construcción genérica claramente perniciosa para la mujer; por este caso es necesario proceder a su re/lectura y a su re/escritura" (Fernández, 1998, p. 210211).

Siguiendo el texto, se cita a Simone de Beauvoir, para señalar que el cuento infantil resalta temas como la pasividad y la belleza; y, a Teresa de Lauretis, quien alude a la renuncia del deseo en la mujer, para que se centre solo en satisfacer el masculino.

Expone que los riesgos que encierra el mensaje transmitido en el cuento es que a la mujer le sea imposibilitado el acceso al binomio conocimiento - creación y que las centre en un espacio de desconocimiento y función procreadora.

Para los análisis feministas, la heroína es un modelo de mujer construida según el modelo de femineidad patriarcal que resulta negativo, por ello las reescrituras que se han venido produciendo.

\section{Diversas reescrituras del cuento de la bella durmiente}

El cuento de hadas como cualquier texto literario permite multitud de lecturas según la época o la experiencia vital y literaria del lector. A este respecto se encuentra que:

El cuento estimula múltiples niveles de lectura y la relación que el individuo establece con él no se agota con la infancia, sino que lo acompaña en el curso de su existencia (...) descubrirá que para él ese libro significa algo nuevo, encontrará nexos inéditos y contenidos sorprendentes (Correa y Perera, 2007, p. 488). 
Sin embargo, existen corrientes dentro de la literatura que sostienen que es necesario reescrituras de conocidos relatos, que si bien se gestaron en un sistema cultural y literario de una época concreta “...es precisamente el distanciamiento de ese sistema y, con ello, la dificultad de comprensión para lectores no muy cualificados lo que induce a la reescritura" (Sotomayor, 2005,p. 228).

Bados (2007) nos aporta que, desde mediados del siglo XX, con el aumento de escritoras, el posicionamiento de la crítica feminista y los estudios de género, se han promovido las reescrituras de los cuentos de hadas, con el fin de subvertir y desmantelar el discurso patriarcal que los atraviesa.

Procederé a presentar reescrituras recogidas por Fernández (1998), las que están realizadas sobre la versión de Perrault o la de los hermanos Grimm; y las agrupa en dos tipos: aquellas que no atacan a la ideología patriarcal y están motivadas por diversas intenciones como la humorística, paródica, pornográfica, terapéutica y recreativa, entre otras, y las feministas que intentan, con su discurso, deconstruir los arquetipos patriarcales y proponer sistemas alternativos.

Las reescrituras feministas intentan deconstruir tres arquetipos patriarcales: "gracias de la femineidad", donde se incluyen cuestiones como la pasividad, la belleza, la virginidad, etc.; el del libertador y el del matrimonio, como único objetivo posible de la mujer para conducirla a la felicidad. Estas se han basado en la versión de los hermanos Grimm, en donde se desconoce qué sucedió luego de la unión de los héroes. Al parecer los autores alemanes intentaron reforzar los arquetipos del héroe, el matrimonio y la mujer bella, pasiva y virgen.

La deconstrucción de los arquetipos ha permitido diversas confecciones según el rasgo a combatir. Fernández (1998) nos presenta algunas reescrituras de las "gracias de la femineidad", como la de Marco Denevi, que critica la construcción pasiva de la mujer; Suniti Namjoshi trata la impotencia de las heroínas femeninas tradicionales; Ann Downer y Emma Donoghue relacionan la impotencia femenina y la falta de conocimiento, adicionando alternativas al presentar heroínas que acceden al conocimiento, con el objeto de salir de las designaciones clásicas de indefensión y desvalimiento; y la de Angela Cartner, considerada subversiva porque la heroína asume el papel de agresor; mientras que el soldado, el de víctima indefensa e ignorante.

El rasgo del libertador, podemos verlo en reescrituras como las de Angela Cartner donde el héroe condena y no protege; así como en las de Luisa Valenzuela,que le adicionan aspectos en su comportamiento traducidos por mezquindad y egoísmo.

El rasgo de matrimonio es trabajado por Jill MacCorkle y Luisa Valenzuela, quienes dividen a las heroínas en aquellas que son capaces de escaparse del matrimonio, otras que aunque no lo logran no las descalifican y las últimas que son incapaces de evitarlo.

Es importante rescatar que:

Las revisiones feministas de la "Bella Durmiente", sin embargo, nos demuestran que la realidad puede ser construida de múltiples formas, re- 
chazando así la concepción unitaria de verdad y proponiendo, en cambio, una pluralidad de verdades (Fernández, 1998, p. 216).

Esta propuesta literaria desde el enfoque feminista nos entrega una pluralidad de soluciones para un mismo caso y nos deja apreciar cómo una misma solución puede ser útil para más de un caso. Así las revisiones feministas se alejan del sistema patriarcal y de su manera de representar la realidad; defienden la percepción múltiple de la realidad, una pluralidad de verdades y una multitud de opciones.

Finalmente, señalar que es necesario estudios a profundidad en los diversos campos comunicacionales, y en este en especial, que nos lleva a replantearnos cómo los discursos aceptados y transmitidos por pertenecer al campo científico - cultural favorecen la construcción de identidades que pudieran seguir sosteniendo el modelo aún hegemónico, pero que el esfuerzo de revertirlos en nuevas propuestas nos posibilitarían construirnos con mayor libertad.

\section{CONCLUSIONES}

1. Las diferentes manifestaciones artísticas están integradas por arquetipos sociales que pertenecen al imaginario colectivo de una determinada sociedad.

2. Los cuentos de hadas son una práctica cultural que configura la organización social en función del género y transmite valores éticos, afectivos y corporales.

3. Las versiones tradicionales proponen estereotipos de un poder y libertad absolutos asignados al varón, mientras las mujeres serán buenas o malas según cumplan los ideales patriarcales de la femineidad.

4. Los enfoques ofrecen explicaciones desde sus postulados teóricos y plantean significados en los símbolos empleados en los cuentos tradicionales.

5. Las reescrituras esbozan maneras de subvertir las expectativas según las cuales las mujeres se hallaban limitadas a sus roles como esposas y madres, sugieren modelos alternativos frente a ello, denunciando los estereotipos y resistiéndose al poder patriarcal.

6. Las reescrituras son discursos con una mirada divergente frente a los estereotipos tradicionales y proponen una literatura lúdica y llena de significados alternativos.

\section{REFERENCIAS BIBLIOGRÁFICAS}

Bados, C. (2007). Los cuentos de hadas desde una perspectiva de género: la ironía como artificio subversivo. Ponencia presentada en el X Simposio Internacional Lengua, Literatura y Género de la SEDLL. Baeza, España. 28-30 noviembre, 494-508.

Bettelheim, B. (1990). Psicoanálisis de los cuentos de hadas. Barcelona: Crítica.

Correa, J. y Perera, A. (2007). Ni tan bellas ni tan buenas: el canon de la belleza en la literatura infantil. Ponencia presentada en el X Simposio Internacional 
Lengua, Literatura y Género de la SEDLL. Baeza, España. 28-30 noviembre, 481-493.

De La Concha, A. (Coord.). (2010). El sustrato cultural de la violencia de género. Madrid: Síntesis.

Fernández, C. (1998). La bella durmiente a través de la historia. Oviedo: Servicio de Publicaciones de la Universidad de Oviedo.

Salmueron, P. (2004). Transmisión de valores a través de los cuentos clásicos infantiles. Tesis doctoral. Universidad de Granada, España. Recuperado de http://hera.ugr.es/tesisugr/15487441.pdf.

Sotomayor, M. (2005). Literatura, sociedad, educación: las adaptaciones literarias. Educación. España, Ministerio de Educación, Cultura y Deporte, Núm. Extraordinario 2005, 217-238. 